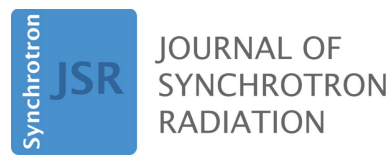

ISSN 1600-5775

Received 4 October 2021

Accepted 7 December 2021

Edited by S. Butorin, Uppsala University, Sweden

Keywords: extended X-ray absorption fine structure (EXAFS); actinide; plutonium; cerium; nanoparticles; coordination number.

Supporting information: this article has supporting information at journals.iucr.org/s

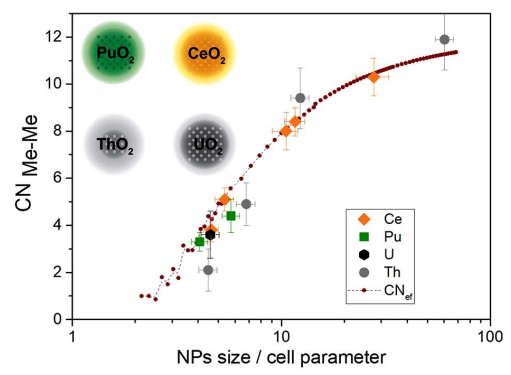

OPEN $\odot$ ACCESS

\section{Effective coordination numbers from EXAFS: general approaches for lanthanide and actinide dioxides}

\author{
Anna Romanchuk, ${ }^{a *}$ Alexander Trigub, ${ }^{\text {a,b }}$ Tatiana Plakhova, ${ }^{a}$ \\ Anastasiia Kuzenkova, ${ }^{a}$ Roman Svetogorov, ${ }^{b}$ Kristina Kvashnina, ${ }^{a, c, d}$ and \\ Stepan Kalmykov ${ }^{\mathrm{a} *}$
}

\begin{abstract}
${ }^{\mathbf{a}}$ Department of Chemistry, Lomonosov Moscow State University, Leninskie Gory 1, Bld. 3, Moscow 119991, Russian Federation, 'b National Research Centre 'Kurchatov Institute', PI. Kurchatova 1, Moscow 123182, Russian Federation, ${ }^{\mathbf{c}}$ The Rossendorf Beamline at ESRF - The European Synchrotron, CS40220, 38043 Grenoble Cedex 9, France, and dInstitute of Resource Ecology, Helmholtz-Zentrum Dresden-Rossendorf (HZDR), PO Box 510119, 01314 Dresden, Germany. *Correspondence e-mail: romanchuk.anna@gmail.com, stepan@radio.chem.msu.ru
\end{abstract}

Extended X-ray absorption fine structure (EXAFS) is a comprehensive and usable method for characterizing the structures of various materials, including radioactive and nuclear materials. Unceasing discussions about the interpretation of EXAFS results for actinide nanoparticles (NPs) or colloids were still present during the last decade. In this study, new experimental data for $\mathrm{PuO}_{2}$ and $\mathrm{CeO}_{2}$ NPs with different average sizes were compared with published data on $\mathrm{AnO}_{2}$ NPs that highlight the best fit and interpretation of the structural data. In terms of the structure, $\mathrm{PuO}_{2}, \mathrm{CeO}_{2}, \mathrm{ThO}_{2}$, and $\mathrm{UO}_{2}$ NPs exhibit similar behaviors. Only $\mathrm{ThO}_{2}$ NPs have a more disordered and even partly amorphous structure, which results in EXAFS characteristics. The proposed new core-shell model for NPs with calculated effective coordination number perfectly fits the results of the variations in a metal-metal shell with a decrease in NP size.

\section{Introduction}

Plutonium dioxide $\left(\mathrm{PuO}_{2}\right)$ is a crucial component of modern atomic energy (Clark et al., 2005, 2019; McFarlane, 2004). A possible strategy for the nuclear power cycle is to use mixedoxide fuels that contain 3-5\% $\mathrm{PuO}_{2}$ (Carbajo et al., 2001). In contrast, $\mathrm{PuO}_{2}$ in particulate and colloidal forms is important in the context of radioecology and environmental safety. Colloidal transport of plutonium in the environment was found to be the predominant mechanism of subsurface migration (Kersting et al., 1999; Novikov et al., 2006). These findings make it necessary to conduct careful studies of both pseudo- and intrinsic plutonium-containing colloidal particles.

However, despite its practical importance, $\mathrm{PuO}_{2}$ is even more intriguing from a fundamental perspective. Indeed, considering the periodic system, it is not easy to find cations that can be present as $\mathrm{Me}^{4+}$ (where Me indicates a metal) in aqueous solutions. This list mainly includes $\mathrm{Th}^{4+}, \mathrm{U}^{4+}, \mathrm{Np}^{4+}$, $\mathrm{Pu}^{4+}$, and one lanthanide $\mathrm{Ce}^{4+}$. All tetravalent lanthanides and actinides, such as $\mathrm{Th}, \mathrm{U}, \mathrm{Np}, \mathrm{Pu}$, and $\mathrm{Ce}$, have a high tendency to form $\mathrm{MeO}_{2}$ precipitates in the form of nanoparticles (NPs) (Powell et al., 2011; Romanchuk et al., 2018; Gerber et al., 2020), or sometimes referred to as polymers or eigen/intrinsic colloids (Silver, 2001; Rai \& Swanson, 1981; Costanzo et al., 1973; Triay et al., 1991; Thiyagarajan et al., 
1990). Meanwhile, plutonium stands out in this series because of its complicated chemistry with redox reactions and high radiotoxicity.

Extended X-ray absorption fine structure (EXAFS) is a powerful method for characterizing the local structure of nanostructured materials (Kuzmin \& Chaboy, 2014; Rehr \& Albers, 2000; Lee et al., 1981). This method is element-selective, non-destructive, and relatively moderate for the sample during measurements (no vacuum, heating, and ionization), making it one of the most popular and widely used techniques for characterizing radioactive materials.

Although EXAFS has been widely used for the characterization of $\mathrm{PuO}_{2}$, compared with other methods, the interpretation of the results is still debatable. Conradson et al. (2004) distinguished up to eight individual components in the first coordination shell of plutonium dioxide, which corresponds to the interaction of plutonium atoms with neighboring oxygen atoms. The authors proposed a chemical formula for the colloids as $\mathrm{PuO}_{2+x-y}(\mathrm{OH})_{2 y} \cdot z \mathrm{H}_{2} \mathrm{O}$, where $x$ indicates the $\mathrm{Pu}(\mathrm{V})$ species due to the presence of the $\mathrm{Pu}(\mathrm{V})-\mathrm{O}$, plutonoyl, component at $\sim 1.9 \AA$. However, in the study by Rothe et al. (2004), this short distance was attributed to multi-electron excitation and thus excluded from consideration. They isolated two components from EXAFS, the first with a $\mathrm{Pu}-\mathrm{O}$ distance of $2.20-2.24 \AA$, and the second with a $\mathrm{Pu}-\mathrm{O}$ distance of $2.38-2.42 \AA$. The shorter distance was attributed to the interaction of the plutonium atom with the hydroxo-group or with the oxygen atom of the water molecule. In contrast, Hudry et al. (2014) isolated only one component, $\mathrm{Pu}-\mathrm{O}$, in the EXAFS spectrum of $\mathrm{PuO}_{2}$ nanocrystals with a distance of $2.31 \AA$, which is slightly less than that of bulk $\mathrm{PuO}_{2}$. A slight decrease in the coordination number $(\mathrm{CN})$ in the first and second coordination shells was observed. Dalodière et al. (2017), in their study of $\mathrm{PuO}_{2}$ NPs obtained by both hydrolytic and sonolitic methods, reported a split in the first coordination shell of plutonium and identified three different interatomic interactions: short (1.93-2.23 $\AA$ ), medium (2.23-2.63 $\AA$ ), and long (2.63-3.13 $\AA$ ) ranges. In this case, the short component corresponds to $\mu_{1}-\mathrm{Pu}-\mathrm{OH}$ or $\mu_{3}-\mathrm{Pu}-\mathrm{O}$, the medium component corresponds to $\mu_{4}-\mathrm{O}$ from the $\mathrm{PuO}_{2}$ ideal structure, and the long component corresponds to the surface-adsorbed $\mathrm{H}_{2} \mathrm{O}$ molecules. In the continuation of this study, Bonato et al. (2020) suggested that the splitting is due to the disordered crystal structure of the NPs. Recently, the interpretation of EXAFS spectra was revised by Micheau et al. (2020). The authors used a single $\mathrm{Pu}-\mathrm{O}$ scattering path to fit a Fourierfiltered oxygen shell and determined the corresponding Debye-Waller factor (DWF) as the only floating parameter. In the paper by Gerber et al. (2020), using different approaches including Landweber iteration and Monte Carlo simulation proved the absence of legitimate reasons to split the $\mathrm{Pu}-\mathrm{O}$ shell in $\mathrm{PuO}_{2}$ NPs.

This study aims to compare EXAFS data for tetravalent $\mathrm{CeO}_{2}, \mathrm{ThO}_{2}, \mathrm{UO}_{2}$, and $\mathrm{PuO}_{2}$ NPs of various sizes and compare several approaches for fitting the EXAFS spectra.

\section{Experimental}

2.1. Synthesis and characterization of $\mathrm{CeO}_{2}$ and $\mathrm{PuO}_{2} \mathrm{NPs}$ of various sizes

Cerium dioxide NPs were synthesized via rapid chemical precipitation. In this synthesis approach, both the type and concentration of the starting salt affect the particle size. Cerium (IV) ammonium nitrate, $\left(\mathrm{NH}_{4}\right)_{2} \mathrm{Ce}\left(\mathrm{NO}_{3}\right)_{6}$, and cerium (III) nitrate hexahydrate, $\mathrm{Ce}\left(\mathrm{NO}_{3}\right)_{3} \cdot 6 \mathrm{H}_{2} \mathrm{O}$, were used to prepare the initial cerium solutions. Concentrations of the salts varied from 0.01 to $0.8 \mathrm{M}$. Aqueous solutions of the cerium salts were added to $3 M$ aqueous solution in molar excess under constant stirring, resulting in the formation of yellow suspensions. The precipitates were separated by centrifugation and washed three times with Milli-Q water to remove any impurities. For further measurements, the samples were air-dried for $24 \mathrm{~h}$ at $40^{\circ} \mathrm{C}$. A sample synthesized from $0.1 M\left(\mathrm{NH}_{4}\right)_{2} \mathrm{Ce}\left(\mathrm{NO}_{3}\right)_{6}$ was additionally annealed for $12 \mathrm{~h}$ at $400^{\circ} \mathrm{C}$ in a muffle furnace.

Plutonium dioxide was formed as a result of the long storage (375 days) of $\mathrm{Pu}(\mathrm{VI})$ solution at a total $\mathrm{Pu}$ concentration of $10^{-4} M$ at $\mathrm{pH} \sim 8$ and 12 .

Synchrotron-based X-ray diffraction (XRD), performed at the XSA beamline (Svetogorov et al., 2020) of the Kurchatov Synchrotron Radiation Source (Moscow, Russia) using a Rayonix SX165 detector, was employed to characterize the inorganic matrix of the bottom sediments. Diffraction patterns were obtained using monochromatic radiation with a wavelength of $\lambda=0.8 \AA$ focused on a spot of $400 \mu \mathrm{m}$ of a sample held in a polymer capillary in the case of Pu-containing substances and a cryoloop in the case of $\mathrm{CeO}_{2}$. Two-dimensional diffraction patterns were further transformed using Dionis software to reveal the dependence of the intensity on the scattering angle.

The average particle size of the $\mathrm{CeO}_{2} \mathrm{NPs}$ was calculated from the XRD data using different procedures. It was calculated from the broadening of the diffraction lines using both the Scherrer equation and Williamson-Hall approach. The full width at half-maximum (FWHM) parameter was estimated from the diffraction peaks fitted by the pseudo-Voigt function. Instrumental broadening was calculated using the Caglioti formula (Caglioti et al., 1958) and considered when calculating the particle size by direct subtraction from the FWHM values. Determination of the unit-cell parameters and calculation of the values of the crystallite size and microstress influence were performed using Rietveld refinement in the Jana2006 software (Petříček et al., 2014) (see example in Fig. S1C of the supporting information). Instrumental broadening was determined using the LaB6 certified crystallographic standard (NIST SRM 660a). A comparison of the $\mathrm{CeO}_{2}$ NP sizes determined by different approaches is summarized in Table S1 of the supporting information. The size of the $\mathrm{PuO}_{2}$ crystallites was estimated from the broadening of the first four diffraction peaks [(111), (200), (220), and (311)] using the Scherrer equation. In the $\mathrm{PuO}_{2} \mathrm{XRD}$ data, a substantial contribution of the background diffraction scattering from the capillary was 
observed. Therefore, adequate subtraction of the background during the data procedure is unattainable.

\subsection{EXAFS measurement}

XAFS spectra were collected at the Structural Materials Science beamline (Chernyshov et al., 2009) of Kurchatov Synchrotron Radiation Source (Moscow, Russia). A storage ring with electron beam energy of $2.5 \mathrm{GeV}$ and current in the range $80-100 \mathrm{~mA}$ was used. $\mathrm{Pu} L_{3}$-edge XAFS was measured using an X-ray beam monochromated with a $\mathrm{Si}(220)$ channel-cut monochromator, which provided an energy resolution of $\Delta E / E \simeq$ $2 \times 10^{-4}$. The damping of higher-energy harmonics was achieved by monochromator geometry distortion. The XAFS spectrum of the $\mathrm{Zr}$ foil was used for energy calibration. Ce $L$ edges have a very short energy range ( $440 \mathrm{eV}$ for the $L_{3}$-edge); therefore, only a few parameters could be extracted from the EXAFS spectra measured at $\mathrm{Ce} L$-edges. The $\mathrm{Ce} L_{3}$-edge spectrum also contains the contribution of the multi-electron effect, which should be considered during data treatment. Therefore, Ce $K$-edge XAFS measurements were inspired by the possibility of measuring the EXAFS spectra over a wide $k$-range. Ce $K$-edge XAFS was measured using a $\mathrm{Si}(333)$ channel-cut monochromator, and the $\mathrm{Si}(111)$ reflection was annihilated by an $\mathrm{Al}$ filter with a thickness of $5 \mathrm{~mm}$. All the experimental data were collected in transmission mode using ionization chambers filled with an appropriate mixture of $\mathrm{Ar} / \mathrm{N}_{2}$ for the $\mathrm{Pu} L_{3}$-edge and $\mathrm{Xe}$ for the Ce $K$-edge. At every energy point in the XANES region the signal was integrated for $1 \mathrm{~s}$, whereas for the EXAFS region the integration time was set to $1 \mathrm{~s}$ at the beginning of the region and increased to $4 \mathrm{~s}$ at the end of the region. Samples for $\mathrm{Pu} L_{3}$ measurements were stored in the polymer capillaries during the measurements, but $\mathrm{CeO}_{2}$ powders were pressed into the pallets with appropriate thickness. The beam size for the $\mathrm{Pu} L_{3} \mathrm{X}$-ray absorption spectrometry (XAS) was selected to be suitable for the homogeneous area of the samples, but not less than $500 \mu \mathrm{m} \times 500 \mu \mathrm{m}$ to obtain the appropriate signal-to-noise ratio. For the Ce $K$-edge XAS experiments, we used a beam with a size of $1 \mathrm{~mm} \times 4 \mathrm{~mm}$. For all samples, at least three spectra were collected and merged using IFEFFIT software (Newville, 2001).

\section{Results and discussion}

To distinguish the influence of the particle size on the spectral characteristics, samples of $\mathrm{CeO}_{2}$ and $\mathrm{PuO}_{2}$ with different average particle sizes were studied by XRD. In all the cases, a fluorite-type diffraction pattern was observed (Fig. S1) with a different line broadening, from which the average crystallite size was calculated as described in the Experimental section and Table S1. Consequently, six samples of $\mathrm{CeO}_{2}$ were selected with particle sizes ranging from $\sim 2$ to $20 \mathrm{~nm}$ (Table 1). In the case of $\mathrm{PuO}_{2}$, the particle size varied from 2.0 to $3.2 \mathrm{~nm}$. Bulk samples of $\mathrm{CeO}_{2}$ and $\mathrm{PuO}_{2}$ were used for comparison. The XANES spectra for size series look very similar (Fig. S2).

The magnitudes of the Fourier transform (FT) of the weighted experimental EXAFS spectra for the studied $\mathrm{CeO}_{2}$ and $\mathrm{PuO}_{2}$ NPs are shown in Fig. 1. In all cases, two main shells are clearly distinguished: $\mathrm{Me}-\mathrm{O}$ with the maximum approximately $R-\Delta=1.8 \AA$ and $\mathrm{Me}-\mathrm{Me}$ with the maximum approximately $R-\Delta=3.7 \AA$. Additional peaks or shoulders at 1.15-1.2 $\AA$ in the case of $\mathrm{PuO}_{2}$ spectra result from atomic contributions or multielectron excitations (Rothe et al., 2004). Spectral features between 2 and $3 \AA$ could be attributed to the complicated shape of the contributions of heavy elements (metal in the second coordination shell) and multiple-scattering paths (Bocharov et al., 2017). The contribution of the multiple-scattering paths is visible in the experimental data, but is not essential for modeling the EXAFS spectra of actinide dioxide NPs. With decreasing size, the second coordination shell drastically decreases. The first coordination shell is changed to a decreasing size, but the changes are less definite in this case. The intensity reduction is caused by the decrease in the average $\mathrm{CNs}$ and the distortion in the atomic structure of the NP due to the size effect. The explanation and description of both effects can be found in the appropriate sections.

The following approach was used to fit the experimental EXAFS spectra. First, the EXAFS spectra corresponding to the bulk samples were fitted. In this case, the CNs for the two nearest coordination shells were fixed, but the DWFs and interatomic distances to absorbing atoms were varied. The $\mathrm{CNs}$ for the $\mathrm{Me}-\mathrm{O}$ and $\mathrm{Me}-\mathrm{Me}$ shells were fixed as they should be in the ideal crystal. From this fitting procedure, the DWF for the Me-Me shell was extracted, and they were later used to fit the EXAFS spectra of the NP samples. All spectra were fitted in the $R$-space with $k$-weights of 2 and 3 using symmetric square windows with 'Hanning sills'.

EXAFS spectra for NPs were fitted with varying radii of $\mathrm{Me}-\mathrm{O}$ and $\mathrm{Me}-\mathrm{Me}$ coordination shells, DWF for $\mathrm{Me}-\mathrm{O}$ coordination shells, and $\mathrm{CN}$ for Me-Me shells. Four para- 

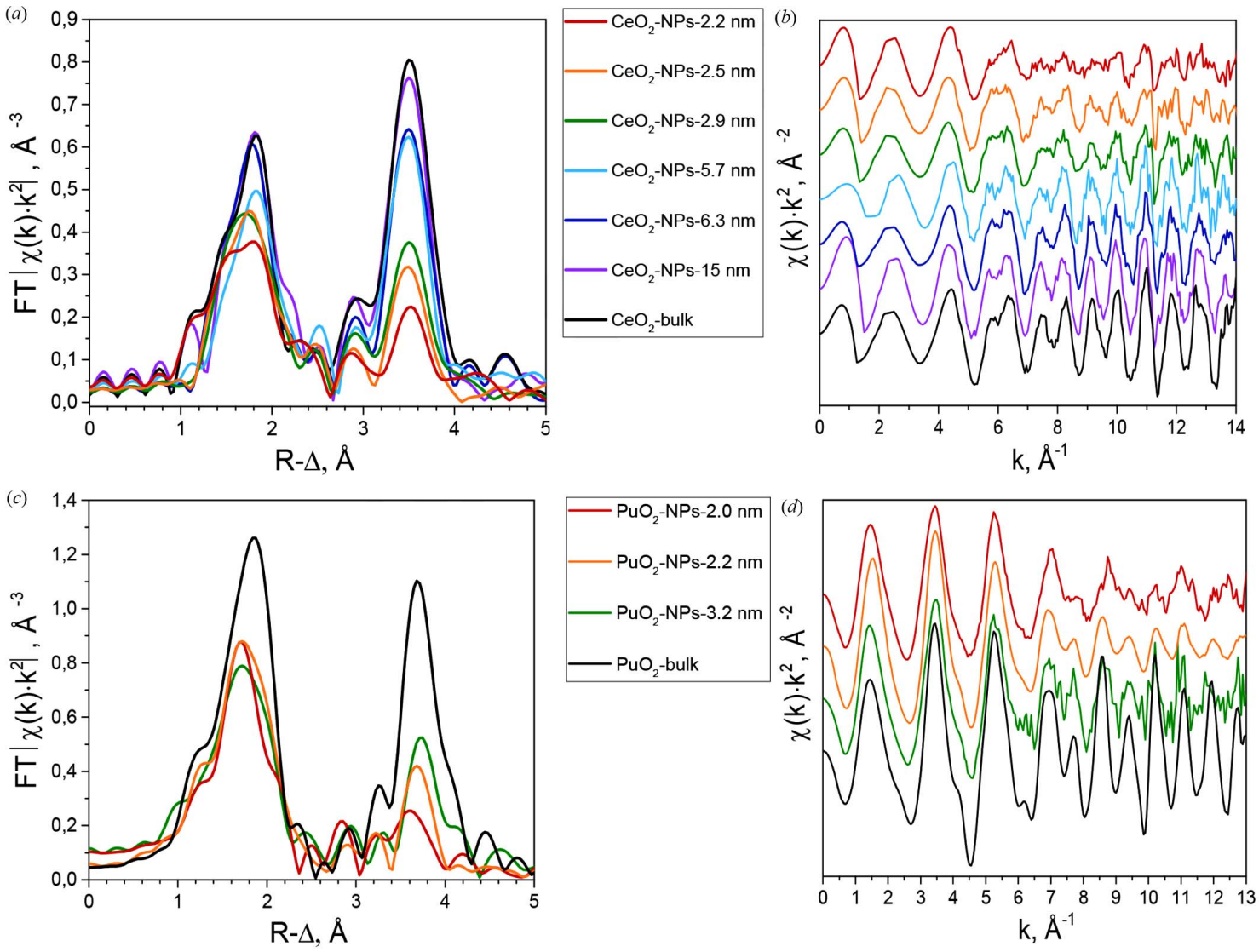

Figure 1

$(a, b)$ Ce $K$-EXAFS: $(a)$ FT magnitude of EXAFS data $(k=3-13),(b) k^{2}$-weighted $\chi(k)$ experimental functions; $(c, d)$ Pu $L_{3}$-EXAFS: $(c)$ FT magnitude of EXAFS data $(k=3-13),(d) k^{2}$-weighted $\chi(k)$ experimental functions.

meters were optimized by fitting the NP EXAFS spectra. The proposed procedure dramatically decreases the number of variables and obtains stable values of fitted structural parameters, which is essential for further reliable structural data treatment. The amplitude reduction factor, $S_{0}^{2}$, was defined as 0.9 in the $F E F F$ calculation and fixed at that value in the data fits, which is typical for actinides and for $K$-edges of heavyatom EXAFS spectra fitting (Prieur et al., 2019). The energy shift parameter $(\Delta E)$ was treated as a variable for the bulk sample, and the obtained value was used for the NPs.

Similar trends were obtained for the $\mathrm{CN}$ of $\mathrm{Me}-\mathrm{Me}$ when the DWF was varied (see Fig. S4). However, relatively high uncertainties in such determination prevent the understanding of the tiny effects on the structure changes with the decrease in the particle size.

The obtained results are summarized in Table 2 and Fig. S3.

\subsection{First oxygen shell (Me-O)}

Interpretation of the first $\mathrm{Me}-\mathrm{O}$ shell in the case of actinide dioxide NPs provokes an intense scientific discussion. A high DWF and non-symmetry indicate extraordinary structural features. As discussed in the Introduction section, some authors proposed to fit this shell by combining several different distances (Conradson et al., 2004; Dalodière et al., 2017; Rothe et al., 2004, 2009). One of the possible inter- pretations of the presence of oxidized $\mathrm{Pu}(\mathrm{V})$ or $\mathrm{Pu}(\mathrm{VI})$ in the structure of $\mathrm{PuO}_{2}$ NPs was confidently rejected (Gerber et al., 2020; Bonato et al., 2020) and will not be further considered in this study. To avoid contrived conclusions resulting from overfitting, some authors have proposed that the first coordination oxygen shell is not split into different subshells (Gerber et al., 2020; Bonato et al., 2020; Micheau et al., 2020). Here, we followed the same strategy. We avoided the isolation of this Me-O shell as in previous studies (Bonato et al., 2020; Micheau et al., 2020), but fixed the $\mathrm{Me}-\mathrm{O} \mathrm{CN}$ and made a variable DWF that is different from Gerber et al. (2020).

Consequently, we showed in this study that the DWF is essentially increased with decreasing NP size (Table 2), which is even more pronounced in the case of $\mathrm{CeO}_{2} \mathrm{NPs}$. The results of this work were compared with previously published data (Fig. 2), along with $\mathrm{ThO}_{2}$.

Despite the slightly different approaches, the results converge well. All NPs $-\mathrm{CeO}_{2}, \mathrm{PuO}_{2}$, and $\mathrm{ThO}_{2}-$ maintained the same trend. With a decrease in the size of the NPs to less than $10 \mathrm{~nm}$, the DWF of the first coordination shell is drastically increased. Such an increase in the DWF correlates with the increasing contribution of the surface atoms (Fig. S5), which indirectly indicates that the disordering effect in the oxygen shell is related to the surface atoms.

Another observation is that DWFs for Me-O shells are generally lower for $\mathrm{ThO}_{2} \mathrm{NPs}$ than for $\mathrm{PuO}_{2}$, and the DWF 
Table 2

Structural parameters obtained from the fitting of EXAFS spectra.

\begin{tabular}{|c|c|c|c|c|c|}
\hline Sample & $\begin{array}{l}\text { Coordination } \\
\text { shell }\end{array}$ & $\begin{array}{l}\text { Coordination } \\
\text { number, CN }\end{array}$ & $\begin{array}{l}\text { Interatomic } \\
\text { distance, } R(\AA)\end{array}$ & $\begin{array}{l}\text { Debye-Waller } \\
\text { factor }\left(\sigma^{2}\right)\left(\AA^{2}\right)\end{array}$ & $\begin{array}{l}R \text {-factor } \\
k \text { range } \\
R \text { range }\end{array}$ \\
\hline \multirow[t]{3}{*}{$\mathrm{CeO}_{2}$-bulk } & $\mathrm{O}$ & $8 \dagger$ & $2.34 \pm 0.02$ & 0.0097 & 0.044 \\
\hline & $\mathrm{Ce}$ & $12 \dagger$ & $3.84 \pm 0.01$ & 0.005 & $4-13$ \\
\hline & $\mathrm{O}$ & $24 \dagger$ & $4.39 \pm 0.08$ & 0.014 & $1.5-4.2$ \\
\hline \multirow{3}{*}{$\mathrm{CeO}_{2}$-NPs-15 nm } & $\mathrm{O}$ & $8 \dagger$ & $2.33 \pm 0.02$ & 0.009 & 0.032 \\
\hline & $\mathrm{Ce}$ & $10.3 \pm 0.8$ & $3.84 \pm 0.01$ & $0.005 \dagger$ & $4-13$ \\
\hline & $\mathrm{O}$ & $10.5 \pm 15.1$ & $4.43 \pm 0.07$ & $0.014 \dagger$ & $1.5-4.2$ \\
\hline \multirow[t]{2}{*}{$\mathrm{CeO}_{2}$-NPs- $6.3 \mathrm{~nm}$} & $\mathrm{O}$ & $8 \dagger$ & $2.33 \pm 0.01$ & 0.0009 & 0.022 \\
\hline & $\mathrm{Ce}$ & $8.4 \pm 0.6$ & $3.83 \pm 0.01$ & $0.005 \dagger$ & $\begin{array}{l}4-13 \\
1.5-4.2\end{array}$ \\
\hline \multirow[t]{2}{*}{$\mathrm{CeO}_{2}$-NPs-5.7 nm } & $\mathrm{O}$ & $8 \dagger$ & $2.33 \pm 0.02$ & 0.0116 & 0.052 \\
\hline & $\mathrm{Ce}$ & $8.0 \pm 0.8$ & $3.84 \pm 0.01$ & $0.005 \dagger$ & $\begin{array}{l}4-13 \\
1.5-4.2\end{array}$ \\
\hline \multirow[t]{2}{*}{$\mathrm{CeO}_{2}$-NPs- $2.9 \mathrm{~nm}$} & $\mathrm{O}$ & $8 \dagger$ & $2.34 \pm 0.02$ & 0.0125 & 0.053 \\
\hline & $\mathrm{Ce}$ & $5.1 \pm 0.5$ & $3.84 \pm 0.01$ & $0.005 \dagger$ & $\begin{array}{l}4-13 \\
1.5-4.2\end{array}$ \\
\hline \multirow{2}{*}{$\mathrm{CeO}_{2}$-NPs- $2.5 \mathrm{~nm}$} & $\mathrm{O}$ & $8 \dagger$ & $2.34 \pm 0.02$ & 0.0161 & 0.068 \\
\hline & $\mathrm{Ce}$ & $3.8 \pm 0.5$ & $3.84 \pm 0.01$ & $0.005 \dagger$ & $\begin{array}{l}4-11 \\
1.5-4.0\end{array}$ \\
\hline \multirow[t]{2}{*}{$\mathrm{CeO}_{2}$-NPs- $2.2 \mathrm{~nm}$} & $\mathrm{O}$ & $8 \dagger$ & $2.35 \pm 0.02$ & 0.0171 & 0.175 \\
\hline & $\mathrm{Ce}$ & $2.6 \pm 0.6$ & $3.87 \pm 0.02$ & $0.005 \dagger$ & $\begin{array}{l}4-11 \\
1.5-4.0\end{array}$ \\
\hline \multirow[t]{3}{*}{$\mathrm{PuO}_{2}$-bulk } & $\mathrm{O}$ & $8 \dagger$ & $2.33 \pm 0.01$ & 0.0061 & 0.016 \\
\hline & $\mathrm{Pu}$ & $12 \dagger$ & $3.82 \pm 0.01$ & $0.004 \dagger$ & $3-14$ \\
\hline & $\mathrm{O}$ & $24 \dagger$ & $4.39 \pm 0.02$ & 0.010 & $1.3-4.2$ \\
\hline \multirow[t]{2}{*}{$\mathrm{PuO}_{2}$-NPs-3.2 nm } & $\mathrm{O}$ & $8 \dagger$ & $2.32 \pm 0.02$ & 0.012 & 0.080 \\
\hline & $\mathrm{Pu}$ & $4.7 \pm 0.7$ & $3.83 \pm 0.01$ & $0.004 \dagger$ & $\begin{array}{l}3-12 \\
13-40\end{array}$ \\
\hline \multirow[t]{2}{*}{$\mathrm{PuO}_{2}$-NPs-2.2 nm } & $\mathrm{O}$ & $8 \dagger$ & $2.31 \pm 0.01$ & 0.011 & 0.028 \\
\hline & $\mathrm{Pu}$ & $3.3 \pm 0.4$ & $3.81 \pm 0.01$ & $0.004 \dagger$ & $\begin{array}{l}3-12 \\
1.3-4.0\end{array}$ \\
\hline \multirow{2}{*}{$\mathrm{PuO}_{2}$-NPs-2.0 nm } & $\mathrm{O}$ & $8 \dagger$ & $2.31 \pm 0.02$ & 0.012 & 0.16 \\
\hline & $\mathrm{Pu}$ & $1.7 \pm 1.1$ & $3.80 \pm 0.03$ & $0.004 \dagger$ & $\begin{array}{l}3-12 \\
1.3-4.0\end{array}$ \\
\hline
\end{tabular}

$\dagger$ Parameters were fixed.

values for $\mathrm{CeO}_{2}$ are consistently higher, even taken from the works of different authors. Additionally, the first shell in the spectra of $\mathrm{ThO}_{2}$ NPs (Fig. S6) is much more symmetrical than that in $\mathrm{CeO}_{2}$, where the splitting appears to be clear.

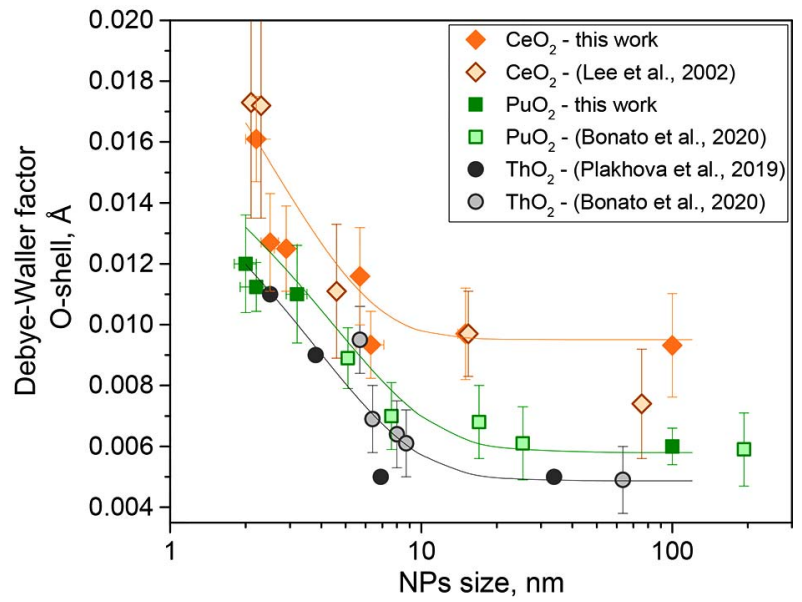

Figure 2

Dependence of the DWF of the first coordination shell $(\mathrm{Me}-\mathrm{O})$ with the average NP size from the results of this work and previously published data.

\subsection{Second coordination shell} (Me-Me)

The CNs of the second $\mathrm{Me}-\mathrm{Me}$ coordination shell obtained from EXAFS spectra fitting were compared for $\mathrm{PuO}_{2}$ and $\mathrm{CeO}_{2}$ NPs of various sizes (Fig. 3). As discussed, $\mathrm{CN}_{\mathrm{Me}-\mathrm{Me}}$ decreased with a decrease in the particle size. To explain this fact, experimental data were compared with the calculated values for spherical NPs as a function of particle size $\left(\mathrm{CN}_{\mathrm{avg}}\right)$. Upon reduction of the NP size, the number of undercoordinated atoms located on the surface increases relative to those in the bulk, thus leading to a decrease in the average CN (Kuzmin \& Chaboy, 2014). This relatively simple geometric consideration did not converge to the experimental data. A similar difference between the experimental $\mathrm{CN}$ and the calculated values was observed for $\mathrm{MoS}_{2}$ (Shido \& Prins, 1998) and in one of our previous studies on the size-dependent series of $\mathrm{ThO}_{2}$ NPs (Plakhova et al., 2019).

To address this problem, we propose a structural model of $\mathrm{MeO}_{2}$. Presumably, $\mathrm{MeO}_{2}$ NPs have a core-shell structure. Metal atoms were suggested to belong to the core of the NP when they contain 12 metal atoms in the second coordination shell; otherwise, metal atoms belong to the shell of the $\mathrm{MeO}_{2}$ NP. The idea is that only the core $\mathrm{Me}$ atoms contribute to the net $\mathrm{Me}-\mathrm{Me} \mathrm{CN}$, but all the Me atoms in the $\mathrm{MeO}_{2} \mathrm{NP}$ contribute to the overall EXAFS signal. Therefore, the effective Me-Me CN $\left(\mathrm{CN}_{\mathrm{ef}}\right)$ can be calculated by normalizing the sum of the $\mathrm{CNs}$ for core atoms to the total number of Me atoms in the particle. The suggested effective $\mathrm{CN}$ can be calculated using the following equation,

$$
\mathrm{CN}_{\text {ef }}=12 \frac{N_{\text {core }}}{N_{\text {total }}}
$$

where $N_{\text {core }}$ denotes the number of $\mathrm{Me}$ atoms in the core and $N_{\text {total }}$ is the total number of Me atoms in the $\mathrm{MeO}_{2} \mathrm{NP}$.

This assumption is in excellent agreement with the experimental results for the $\mathrm{PuO}_{2}$ and $\mathrm{CeO}_{2}$ NPs. Furthermore, this assumption suggests that the EXAFS technique is more sensitive to the highly ordered crystalline core, at least in the case of a second coordination shell.

Using the given assumption, the size of this shell could be estimated as the difference between the radii of the NP and its core part. This calculation provides a value of approximately $0.4 \mathrm{~nm}$, which is close to the cell parameter of the $\mathrm{MeO}_{2}$ crystal structure (Table 3). Recent work (Micheau et al., 2020) 
Table 3

Cell parameter and solubility product constant $\left(K_{\mathrm{sp}}\right)$ for studied series $\mathrm{CeO}_{2}-\mathrm{PuO}_{2}-\mathrm{ThO}_{2}-\mathrm{UO}_{2}$.

\begin{tabular}{llll}
\hline & Cell parameter, $A$ & Reference & $\log K_{\text {sp }}$ \\
\hline $\mathrm{PuO}_{2}$ & 5.396 & $00-041-1170$ & $-58.3 \pm 0.5 \dagger$ \\
$\mathrm{CeO}_{2}$ & 5.4124 & $00-081-0792$ & $-59.3 \pm 0.3 \ddagger$ \\
$\mathrm{UO}_{2}$ & 5.466 & $00-078-0725$ & \\
$\mathrm{ThO}_{2}$ & 5.597 & $00-042-1462$ & $-47.0 \pm 0.8 \S$ \\
\hline
\end{tabular}

$\dagger$ Guillaumont et al. (2003). $\quad \ddagger$ Plakhova et al. (2016). $\S$ Rand et al. (2008).

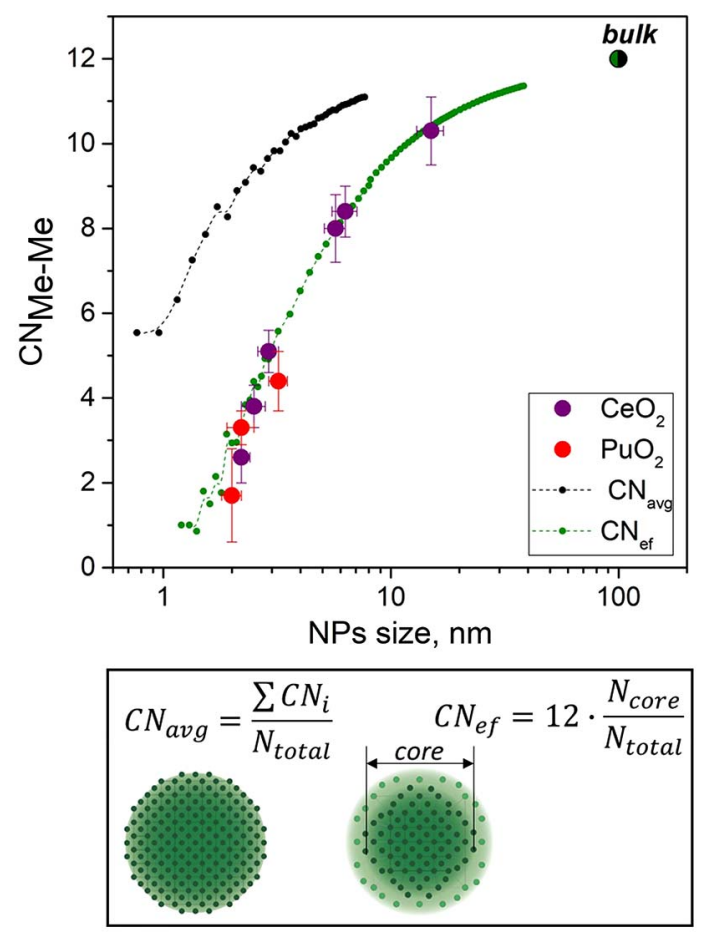

Figure 3

Comparison of the size-dependent change of $\mathrm{Me}-\mathrm{Me} \mathrm{CN}$ in $\mathrm{CeO}_{2}$ and $\mathrm{PuO}_{2}$ NPs, as determined by EXAFS versus calculated values.

also provided insight into the core-shell structure of $\mathrm{PuO}_{2} \mathrm{NPs}$ and determined their size using small-angle X-ray scattering (SAXS). In this study, the size of the shell was estimated to be relatively large (approximately $1.0-1.5 \mathrm{~nm}$ ) and could be interpreted by the presence of a less-ordered shell near the core and a double electric layer near the particles, which is usually accounted for by the SAXS technique.

Notably, the results for $\mathrm{PuO}_{2}$ and $\mathrm{CeO}_{2}$ converged well with each other. This indicates that cerium dioxide can be considered an appropriate analog for $\mathrm{PuO}_{2}$ NPs.

A comparison of the results presented here and published previously for $\mathrm{ThO}_{2}$ (Plakhova et al., 2019) and $\mathrm{UO}_{2}$ NPs (Gerber et al., 2021) is shown in Fig. 4. Because the cell parameters for the studied dioxides were slightly different (Table 3), the NP size values were divided by the cell parameter of bulk $\mathrm{MeO}_{2}$ and used for the $x$-axis (Fig. 4). The clear trend for all series, that is, $\mathrm{CeO}_{2}-\mathrm{PuO}_{2}-\mathrm{ThO}_{2}-\mathrm{UO}_{2}$, remained the same. These results suggest that the proposed core-shell model for $\mathrm{CN}_{\mathrm{ef}}$ is adequate for all the studied $\mathrm{MeO}_{2}$

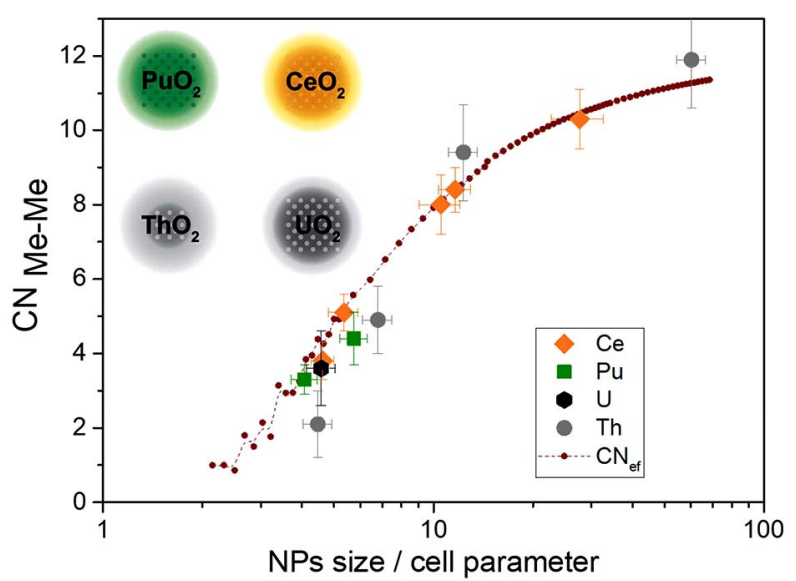

Figure 4

Changes in $\mathrm{Me}-\mathrm{Me} \mathrm{CN}$ with NP size in the series $\mathrm{UO}_{2}-\mathrm{ThO}_{2}-\mathrm{CeO}_{2}-$ $\mathrm{PuO}_{2}$. Data for $\mathrm{ThO}_{2}$ (Plakhova et al., 2019) and $\mathrm{UO}_{2} \mathrm{NPs}$ (Gerber et al., 2021) were taken from our previously published papers.

NPs. Moreover, the results presented here confirm that all NPs have similar structural properties.

In the case of $\mathrm{ThO}_{2}$, the $\mathrm{CN}$ of smaller NPs (less than $10 \mathrm{~nm}$ ) was slightly lower than that of the other studied dioxides. Notably, for the $\mathrm{Me}-\mathrm{O}$ interaction, $\mathrm{ThO}_{2} \mathrm{NPs}$ have a lower DWF than the other studied NPs (presented above), whereas the Me-Me interaction is less pronounced or more disordered. All these findings suggest that, in $\mathrm{ThO}_{2} \mathrm{NPs}$, oxygen atoms are more ordered than more distant atoms, indicating that $\mathrm{ThO}_{2}$ has a more amorphous structure than the other metal dioxides studied. In our latest work (Amidani et al., 2021) on $\mathrm{ThO}_{2}$ NPs using the pair distribution function (PDF) method extracted from high-energy X-ray scattering (HEXS) data, we show that for samples containing very small NPs the first Th-O interaction has a higher intensity than normal. This also indicates better ordering of the first oxygen surroundings. The presence of thorium clusters in a mixture with $\mathrm{ThO}_{2}$ NPs was proposed to fit the PDF data. Similar effects may be present in cases where an increase in the amorphous thickness of the shell near the $\mathrm{ThO}_{2}$ crystalline core occurs. Therefore, it is more evident that $\mathrm{ThO}_{2}$ has a more amorphous nature than $\mathrm{CeO}_{2}, \mathrm{PuO}_{2}$, and $\mathrm{UO}_{2}$. This conclusion has a good correlation with the weakness of the cation $\mathrm{Th}^{4+}$ compared with the other studied cations. This chemical weakness of the $\mathrm{Th}^{4+}$ cation also results in other macro properties, such as higher solubility (higher $\log K_{\mathrm{sp}}$ ) compared with $\mathrm{PuO}_{2}$ and $\mathrm{CeO}_{2}$ (Table 3).

\section{Conclusion}

In this work, we report new EXAFS results of $\mathrm{PuO}_{2}$ and $\mathrm{CeO}_{2}$ NPs with different average sizes and compare them with the published data for $\mathrm{ThO}_{2}$, and $\mathrm{UO}_{2}$ NPs. It was found that the changes observed in the spectra were the same for all series, emphasizing the similarities in the nature and behavior of these dioxide NPs. Only $\mathrm{ThO}_{2}$ demonstrates higher ordering in short-range oxygen surroundings, which is explained by its more amorphous nature, particularly with decreasing NP size. 
Plutonium demonstrated structural characteristics similar to those of the other studied $\mathrm{MeO}_{2}$ NPs.

A conceptual core-shell model with calculated effective $\mathrm{CN}_{\mathrm{ef}}$ was proposed to fit the changes in $\mathrm{CN}$ for the $\mathrm{Me}-\mathrm{Me}$ coordination sphere in the EXAFS spectra of $\mathrm{MeO}_{2} \mathrm{NPs}$. The proposed model perfectly correlates with the experimental results for all studied series and can be used in future studies of other substances.

\section{Related literature}

The following reference, not cited in the main body of the paper, has been cited in the supporting information: Langford et al. (1991).

\section{Funding information}

The work on synthesis, XRD, and EXAFS characterization of $\mathrm{CeO}_{2}$ and $\mathrm{PuO}_{2}$ NPs was funded by the Russian Science Foundation (21-73-20083). AT, KK, and SK acknowledge support from the Russian Ministry of Science and Education under grant No. 075-15-2019-1891 (XAS experimental set-up and technique design). KK acknowledges the European Commission Council under ERC grant N759696.

\section{References}

Amidani, L., Vaughan, G. B. M., Plakhova, T. V., Romanchuk, A. Y., Gerber, E., Svetogorov, R., Weiss, S., Joly, Y., Kalmykov, S. N. \& Kvashnina, K. O. (2021). Chem. Eur. J. 27, 5.

Bocharov, D., Chollet, M., Krack, M., Bertsch, J., Grolimund, D., Martin, M., Kuzmin, A., Purans, J. \& Kotomin, E. (2017). Prog. Nucl. Energy, 94, 187-193.

Bonato, L., Virot, M., Dumas, T., Mesbah, A., Dalodière, E., Dieste Blanco, O., Wiss, T., Le Goff, X., Odorico, M., Prieur, D., Rossberg, A., Venault, L., Dacheux, N., Moisy, P. \& Nikitenko, S. I. (2020). Nanoscale Adv. 2, 214-224.

Caglioti, G., Paoletti, A. \& Ricci, F. P. (1958). Nucl. Instrum. 3, $223-$ 228.

Carbajo, J. J., Yoder, G. L., Popov, S. G. \& Ivanov, V. K. (2001). J. Nucl. Mater. 299, 181-198.

Chernyshov, A. A., Veligzhanin, A. A. \& Zubavichus, Y. V. (2009). Nucl. Instrum. Methods Phys. Res. A, 603, 95-98.

Clark, D., Geeson, D. \& Hanrahan, R. Jr (2019). Plutonium Handbook. American Nuclear Society, La Grange Park, IL, USA.

Clark, D. L., Hecker, S. S., Jarvinen, G. D. \& Neu, M. P. (2005). The Chemistry of the Actinide and Transactinide Elements, edited by L. R. Morss, N. M. Edelstein and J. Fuger, pp. 813-1264. Dordrecht: Springer.

Conradson, S. D., Begg, B. D., Clark, D. L., den Auwer, C., Ding, M., Dorhout, P. K., Espinosa-Faller, F. J., Gordon, P. L., Haire, R. G., Hess, N. J., Hess, R. F., Keogh, D. W., Morales, L. A., Neu, M. P., Paviet-Hartmann, P., Runde, W., Tait, C. D., Veirs, D. K. \& Villella, P. M. (2004). J. Am. Chem. Soc. 126, 13443-13458.

Costanzo, D. A., Biggers, R. E. \& Bell, J. T. (1973). J. Inorg. Nucl. Chem. 35, 609-622.

Dalodière, E., Virot, M., Morosini, V., Chave, T., Dumas, T., Hennig, C., Wiss, T., Dieste Blanco, O., Shuh, D. K., Tyliszcak, T., Venault, L., Moisy, P. \& Nikitenko, S. I. (2017). Sci. Rep. 7, 43514.

Gerber, E., Romanchuk, A. Y., Pidchenko, I., Amidani, L., Rossberg, A., Hennig, C., Vaughan, G. B. M., Trigub, A., Egorova, T., Bauters, S., Plakhova, T., Hunault, M. O. J. Y., Weiss, S., Butorin, S. M.,
Scheinost, A. C., Kalmykov, S. N. \& Kvashnina, K. O. (2020). Nanoscale, 12, 18039-18048.

Gerber, E., Romanchuk, A. Y., Weiss, S., Bauters, S., Schacherl, B., Vitova, T., Hübner, R., Shams Aldin Azzam, S., Detollenaere, D., Banerjee, D., Butorin, S. M., Kalmykov, S. N. \& Kvashnina, K. O. (2021). Inorg. Chem. Front. 8, 1102-1110.

Guillaumont, R., Fanghanel, T., Neck, V., Fuger, J., Palmer, D. A., Grenthe, I. \& Rand, M. H. (2003). Update on the chemical thermodynamics of uranium, neptunium, plutonium, americium and technecium. Amsterdam: OECD Nuclear Energy Agency.

Hudry, D., Apostolidis, C., Walter, O., Janssen, A., Manara, D., Griveau, J. C., Colineau, E., Vitova, T., Prüssmann, T., Wang, D., Kübel, C. \& Meyer, D. (2014). Chem. Eur. J. 20, 10431-10438.

Kersting, A. B., Efurd, D. W., Finnegan, D. L., Rokop, D. J., Smith, D. K. \& Thompson, J. L. (1999). Nature, 397, 56-59.

Kuzmin, A. \& Chaboy, J. (2014). IUCrJ, 1, 571-589.

Langford, J. I., Cernik, R. J. \& Louër, D. (1991). J. Appl. Cryst. 24, 913-919.

Lee, J., Tang, M., Shih, W. C. \& Liu, R. S. (2002). Mater. Res. Bull. 37, 555-562.

Lee, P. A., Citrin, P. H., Eisenberger, P. \& Kincaid, B. M. (1981). Rev. Mod. Phys. 53, 769-806.

McFarlane, H. F. (2004). Encyclopedia of Energy, edited by C. J. Cleveland, pp. 351-364. New York: Elsevier.

Micheau, C., Virot, M., Dourdain, S., Dumas, T., Menut, D., Solari, P. L., Venault, L., Diat, O., Moisy, P. \& Nikitenko, S. I. (2020). Environ. Sci. Nano, 7, 2252-2266.

Newville, M. (2001). J. Synchrotron Rad. 8, 96-100.

Novikov, A. P., Kalmykov, S. N., Utsunomiya, S., Ewing, R. C., Horreard, F., Merkulov, A., Clark, S. B., Tkachev, V. V. \& Myasoedov, B. F. (2006). Science, 314, 638-641.

Petř́íček, V., Dušek, M. \& Palatinus, L. (2014). Z. Krist. 229, 345-352.

Plakhova, T. V., Romanchuk, A. Y., Likhosherstova, D. V., Baranchikov, A. E., Dorovatovskii, P. V., Svetogorov, R. D., Shatalova, T. B., Egorova, T. B., Trigub, A. L., Kvashnina, K. O., Ivanov, V. K. \& Kalmykov, S. N. (2019). J. Phys. Chem. C, 123, 23167-23176.

Plakhova, T. V., Romanchuk, A. Y., Yakunin, S. N., Dumas, T., Demir, S., Wang, S., Minasian, S. G., Shuh, D. K., Tyliszczak, T., Shiryaev, A. A., Egorov, A. V., Ivanov, V. K. \& Kalmykov, S. N. (2016). J. Phys. Chem. C, 120, 22615-22626.

Powell, B. A., Dai, Z., Zavarin, M., Zhao, P. \& Kersting, A. B. (2011). Environ. Sci. Technol. 45, 2698-2703.

Prieur, D. B., Popa, K., Vigier, J., Scheinost, A. C. \& Martin, P. M. (2019). J. Nucl. Mater. 516, 303-308.

Rai, D. \& Swanson, J. L. (1981). Nucl. Technol. 54, 107-112.

Rand, M., Fuger, J., Grenthe, I., Neck, V. \& Rai, D. (2008). Chemical Thermodynamics of Thorium. OECD Nuclear Energy Agency.

Rehr, J. J. \& Albers, R. C. (2000). Rev. Mod. Phys. 72, 621-654.

Romanchuk, A. Y., Plakhova, T. V., Egorov, A. V., Egorova, T. B., Dorovatovskii, P. V., Zubavichus, Y. V., Shiryaev, A. A. \& Kalmykov, S. N. (2018). Dalton Trans. 47, 11239-11244.

Rothe, J., Walther, C., Brendebach, B., Büchner, S., Fuss, M., Denecke, M. A. \& Geckeis, H. (2009). J. Phys. Conf. Ser. 190, 012188.

Rothe, J. J., Walther, C., Denecke, M. A. \& Fanghänel, T. (2004). Inorg. Chem. 43, 4708-4718.

Shido, T. \& Prins, R. (1998). J. Phys. Chem. B, 102, 8426-8435.

Silver, G. L. (2001). J. Radioanal. Nucl. Chem. 247, 561-562.

Svetogorov, R. D., Dorovatovskii, P. V. \& Lazarenko, V. A. (2020). Cryst. Res. Technol. 55, 1900184.

Thiyagarajan, P., Diamond, H., Soderholm, L., Horwitz, E. P., Toth, L. M. \& Felker, L. K. (1990). Inorg. Chem. 29, 1902-1907.

Triay, I. R., Hobart, D. E., Mitchell, A. J., Newton, T. W., Ott, M. A., Palmer, P. D., Rundberg, R. S. \& Thompson, J. L. (1991). Radiochim. Acta, 52-53, 127-132. 